\title{
An Enterprise Knowledge Management System Based on the Use Case Model
}

\author{
Yixin $\mathrm{Li}^{1}$, Nan $\operatorname{Ren}^{2}$ and Sohail S. Chaudhry ${ }^{3}$

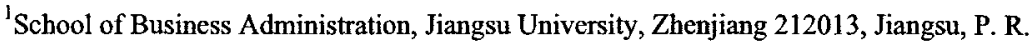 \\ China 1yx@ujs.edu.cn \\ ${ }^{2}$ Economic and Management School, Jiangsu University of Science and Technology, \\ Zhenjiang 212003, Jiangsu, P. R. China rennan hb@sohu.com \\ ${ }^{3}$ Department of Decision and Information Technologies, Villanova School of Business, \\ Villanova University, Villanova, PA 19085, USA sohail.chaudhry@villanova.edu
}

\begin{abstract}
To implement knowledge management within an enterprise requires the implementation of an operational knowledge management system. In this paper we propose a knowledge management scheme for an enterprise that is based on the Use Case model of knowledge management using the Unified Modeling Language. The various functions of the knowledge management system are identified. This study proposes the function-required structure of knowledge management system, establishes a Use Case model of knowledge management with Unified Modeling Language, and delineates the required functions of the enterprise system.
\end{abstract}

Keywords: Knowledge management system, Unified modeling language, Use case model

\section{INTRODUCTION}

Knowledge Management (KM) emerged in the business world during the early 1990's. In literature, researchers have defined KM management based upon their viewpoint. For example, Chow et al. [1] defined KM as the set of activities that enable the creation, storage, distribution, and application of knowledge in organizations; Alavi and Leidner [2] emphasized that KM involves distinct but interdependent processes of knowledge creation, knowledge storage and retrieval, knowledge transfer, and knowledge application; and Davenport and Prusak [3] stated that $\mathrm{KM}$ is a fluid mix of framed experience, values, contextual information and expert insight that provides a framework for evaluating and incorporating new experiences and information.

In 2001, at the KM European Conference, Leif Edvinsson of Skandia stated that "Seventy per cent of the value of the Philips Company is unaccounted for, invisible, intangible. Philips does not need new accounting software; they need a new way of accounting, new reporting systems. This is a common problem in the knowledge economy. Business leaders must ask how they will be paid for their intangibles. Who

Please use the following format when citing this chapter:

Li, Y., Ren, N., Chaudhry, S. S., 2007, in IFIP International Federation for Information Processing, Volume 255, Research and Practical Issues of Enterprise Information Systems II Volume 2, eds. L. Xu, Tjoa A., Chaudhry S. (Boston: Springer), pp. 1141-1146. 
owns their knowledge? Who owns $70 \%$ of your company?" Currently, most of the world renowned enterprises, for example Coca-Cola, Eni, GE, IBM, Shell, and Toyota have introduced the KM within their organizations. Such organizations have appointed a Chief Knowledge Officer (CKO) or equivalent and established a Knowledge Management System (KMS). To introduce KM in an enterprise requires not only the promotion of the new management approach, but also to make the KMS operational. Therefore, how to effectively build, implement, and operate a sound KMS in an enterprise is the key to the smooth implementation of the KM. In this paper we propose a KMS that is based on the Unified Modeling Language (UML) in which the functions are represented by using the Use Case Diagrams.

\section{KNOWLEDGE MANAGEMENT SYSTEM}

Briefly, KMS is used to facilitate the sharing and integration of knowledge, Alavi and Leidner [4]. It is a tool to realize $\mathrm{KM}$ and is an integrated system of index, classification, information searching technology, and management technology enabling customers to access to the information, ( $\mathrm{Li}$ and Hang [5]; $\mathrm{Lu}$ and $\mathrm{Xu}$ [6]). When a design of an enterprise KMS system is carried out, the developers should clearly define the users who will use KMS, understand their requirement for KMS, conduct a system analysis and design of KMS, adopt an advanced modeling tool to accurately depict system model. Next, we present a framework for the realization of KMS to achieve this goal.

\section{KNOWLEDGE MANAGEMENT SYSTEM REQUIREMENTS}

The functional requirements of enterprise KMS should include the employee accesses the system using a unique personal ID; the CKO is able the change the knowledge level in the knowledge base, dispose the request of employee; the employee can browse and retrieve knowledge; the senior manager can assess the knowledge contribution of the employee; and the system administrator can maintain the system and the data. The KMS system based on the above-mentioned requirement mainly includes the following five modules: User logon module; Knowledge obtain module; Knowledge communication module; Evaluation module; and System and data maintenance module.

\section{USE CASE MODEL FOR THE KMS}

We adopt the Unified Modeling Language (UML) to develop the model for the KMS. UML is a general-purpose modeling language which includes a graphical details used to create an abstract model of a system (Rumbaugh et al. [7]). In addition, we utilize the Use Case Diagram to depict the functions of the system. The Use Case model describes how a user of the system, also known as an actor, will interact with 
the system to accomplish a task (Cockburn [8]). In other words, Use Cases describe the sequence of events that an actor progresses through when using a system to accomplish a desired business goal. A Use Case typically consists of actors, pre and post conditions of an interaction with a system, and a description of the systems response. It is important to note, that actors in a Use Case do not represent individuals but rather the roles that are performed by individuals.

Use Case Diagram is the core of other views in the whole procedure of UML modeling. Its contents directly drives the matter of other views, the system wants to provide of the functions all are depicted in the use case.

\subsection{Top Layer Use Case Diagram}

According to system requirements, we set up the top layer Use Case Diagram as shown in Figure 1. Each Use Case is a quick sequence that an actor has something to do with system. The top layer Use Case has the following characteristics:

1. Use Case

- Knowledge Obtain: Employees and external experts provide knowledge for the system. The new knowledge joins the knowledge base after sieving and refining.

- Knowledge Communication: Employees discover the knowledge that they need through Catalog Browse function. They can query and retrieve knowledge from the system.

- Evaluation: Senior (High) Managers assess employee's contribution to the enterprise knowledge. There are <<use >> relation between the Use Case and statistics Use Case. The statistics of system is the basis of evaluation.

- Statistics: The frequency of login and the contribution of the employee to the enterprise knowledge are noted by system. The results of these statistics are basis of evaluation.

- System Maintenance: Administrator carries out the maintenance of the system and guarantees the normal operation of the system.

- Data Maintenance: Administrator maintains the system data and guarantees data security.

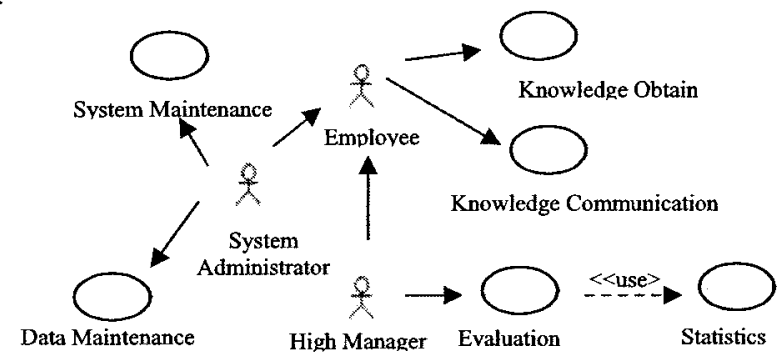

Figure 1. The Top Layer Use Case

\section{Actor}

- Employee: Enterprise employees

- Senior (High) Manager: It is the Son of employee class with a generalized relationship with the employee class. 
- System Administrator: It is the Son of employee class with a generalized relationship with the employee class.

- External Experts: They provide knowledge for the enterprise.

\subsection{The Descendant Use Case of System Model}

\subsubsection{Knowledge Obtain Use Case Diagram}

The Knowledge Obtain Use Case in Figure 1 can subdivided into Knowledge Obtain Use Case Diagram as shown in Figure 2. The characteristics are:

\section{Use Case}

- Ask: The enterprise employees can submit their own questions into the system. It is possible that for some subjects the system would be directed to outside experts.

- Knowledge Solve: The enterprise employees can answer other employees' questions as well as the CKO can give answers obtained from outside experts.

- Internal Knowledge Abstract: CKO will carry through encoding and refining from the knowledge of enterprise internal knowledge acquisition.

- External Knowledge Abstract: CKO will carry through encoding and refining from the knowledge of enterprise external knowledge acquisition.

- Offer Relevant Knowledge: The outside experts provide a relevant knowledge to the enterprise according to the requirements of the enterprise.

2. Actor

- Knowledge Director: The CKO is the vital part of the KMS. It is the Son of employee class and there exist a generalized relationship with the employee class.

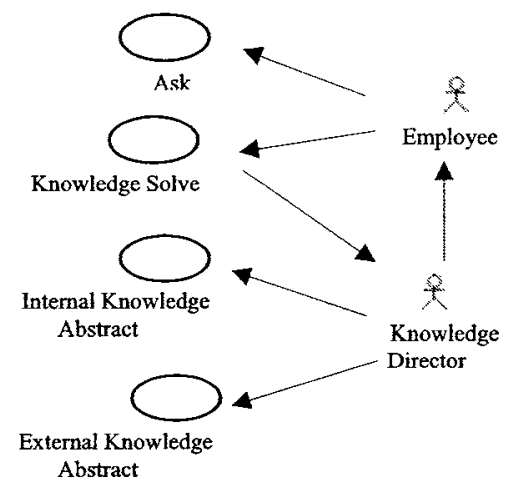

Figure 2. Knowledge Obtain Use Case 


\subsubsection{Knowledge Communication Use Case}

The Knowledge Communication Use Case in Figure 1 can subdivided into Knowledge Communication Use Case Diagram as shown in Figure 3. The characteristics are:

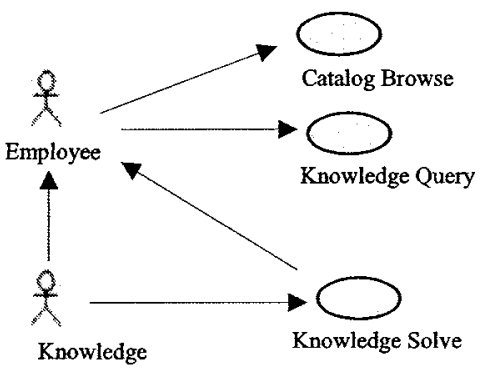

Figure 3. Knowledge Communication Use Case

- Catalog Browse: After login, the enterprise employees can browse the knowledge base system according to their own access rights.

- Knowledge Query: Enterprise employees can query the relevant knowledge by using keywords that they want to understand based on their own access rights.

- Knowledge Solve: The enterprise employee can attain the solution to own question or other employees.

\subsubsection{Authentication Use Case}

Figure 4 represents the Authentication Use Case Diagram. The Authentication Use Case is used by Knowledge Obtain Use Case and Knowledge Communication Use Case.

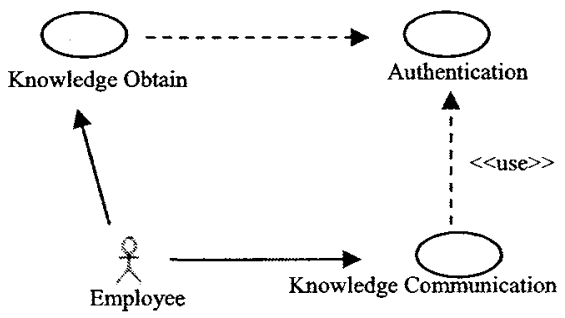

Figure 4. Authentication Use Case

When the employee accesses the system, they must logon first and validate their identity. Each employee has an exclusive ID and code. The different employees have 
different access rights. The system functions according to the access rights of the employee.

\section{CONCLUSIONS}

From the macrocosmic view, KMS of each enterprise is almost identical, so the establishment of KMS Use Case model, the function of depicting target system, can provide function guidance for building enterprise KMS. Certainly, there are differences among various enterprises and so the setup of an actual KMS can still be based on a thorough analysis of system static state structure model and behavioral model. Future research will address this and other related issues.

\section{ACKNOWLEDGEMENTS}

This research was supported by Project of Soft Science supported by Jiangsu province. Study on Model for knowledge management platform which improves hightech type enterprise creative ability (Grant NO. BR2006507); Project of Soft Science supported by Zhenjiang city. Study on Model for knowledge management platform which improves enterprise creative ability (Grant NO. RK2006035); and Project supported by Jiangsu University humanities and social science Foundation. Study on Model for knowledge management platform which improves Chinese medium and small enterprises undertaking independent creative ability (Grant NO. JDR2005035).

\section{REFERENCES}

1. H.K.H. Chow, K.L. Choy, W.B. Lee, and F.T.S. Chan, Design of a knowledge-based logistics strategy system, Expert Systems Applications. Volume 29, pp.272-290, (2005).

2. M. Alavi and D.E. Leidner, Knowledge management and knowledge management systems: Conceptual foundations and research issues, MIS Quarterly. Volume 25, Number 1, pp.107-136, (2001).

3. T.H. Davenport and L. Prusak, Working Knowledge (Harvard Business School Press: Boston, 1998), pp.35-90.

4. M. Alavi and D.E. Leidner, Knowledge management systems: Issues, challenges, and benefits, Communications of the Association of Information Systems. Volume 1, Number 2, (1999).

5. L. Tu and $\mathrm{H}$. Tu, Research on the model architecture and key technologies of knowledge management system, Information Science. Volume 23, Number 1, pp.111-113, (2005).

6. $\mathrm{X}$. $\mathrm{Lu}$ and $\mathrm{H}$. Xu, Some cognition of knowledge management and knowledge management system, Chinese Business Review. Number 8, pp.68-70, (2003).

7. J. Rumbaugh, I. Jacobson, and G. Booch, The Unified Modeling Language Reference Manual, 2nd Edition (Addison-Wesley Professional: Boston, 2005).

8. A. Cockburn, Writing Effective Use Cases (Addison-Wesley Professional: Boston, 2001). 